American Journal of Nanotechnology 1 (1): 13-22, 2010

ISSN 1949-0216

(C) 2010 Science Publications

\title{
Natural Sensitizer for Dye-Sensitized Solar Cells Using Three Layers of Photoelectrode Thin Films with a Schottky Barrier
}

\author{
${ }^{1}$ Ho Chang, ${ }^{2}$ Mu-Jung Kao, ${ }^{3}$ Tien-Li Chen, ${ }^{4}$ Chin-Guo Kuo, \\ ${ }^{5}$ Kun-Ching Cho and ${ }^{1}$ Xiu-Ping Lin \\ ${ }^{1}$ Department of Mechanical Engineering, \\ ${ }^{2}$ Department of Vehicle Engineering, \\ ${ }^{3}$ Department of Industrial Design, \\ National Taipei University of Technology, No.1, Sec. 3, \\ Chung-Hsiao E. Rd., Taipei 10608, Taiwan, China \\ ${ }^{4}$ Department of Mechatronic Technology, \\ National Taiwan Normal University, No.162, Sec. 1, \\ Ho-Ping E. Rd., Taipei 10610, Taiwan, China \\ ${ }^{5}$ Department of Civil Engineering, Texas A and M University, \\ College Station, TX 77843-3136, USA
}

\begin{abstract}
Problem statement: This study combines Au nanoparticles with $\mathrm{TiO}_{2}$ nanoparticles to form a Schottky barrier and applies it to the photoelectrode thin film of Dye-Sensitized Solar cells (DSSCs). Approach: First, commercial $\mathrm{TiO}_{2}$ powder (Degussa P25) was put into the alkaline solution to prepare TiO nanotubes (Tnt) by a hydrothermal process. Tnt were sintered at $550^{\circ}$ to obtain $\mathrm{TntC} 550$ particles and fabricated into a translucent sol by two hydrothermal treatments and baked at $180^{\circ}$ to acquire H180 particles. H180 and TntC550 were spread into transparent polymer films by a doctor blade. H180 serves as the first layer and TntC550 the second, with both were sintered at $450^{\circ}$. The third layer uses hydrogen tetrachloroautate $\left(\mathrm{HAuCl}_{4}\right)$ and trisodium citrate $\left(\mathrm{C}_{6} \mathrm{H}_{5} \mathrm{Na}_{3} \mathrm{O}_{7}\right)$ to prepare $\mathrm{Au}$ nanoparticles by salt reduction. Natural dyes of bougainvillea leaves for chlorophyll and blueberries for anthocyanin were employed in this study. Extracted chlorophyll and anthocyanin dyes were also blended in the proportion of 1: 1 as a mixed dye and these three different natural dyes were compared to compare their photoelectric conversion efficiencies. Electrolyte and counter electrode $(\mathrm{Pt})$ were added to form the sandwich structure of DSSCs. After being sealed, DSSCs were tasted for fill factor, photoelectric conversion efficiency and incident photon-to-current conversion efficiency. Results: Spherical Au nanoparticles around $27 \mathrm{~nm}$ were adhered to the TntC550 make a film by self-assembly to complete the preparation of the third of photoelectrode thin film of DSSCs. Results from the experimental tests show that for the dye mixtures, photoelectric conversion efficiency of DSSCs in this study can reach $0.75 \%$ with the $\mathrm{V}_{\mathrm{OC}}$ of $0.56 \mathrm{~V}$ and $\mathrm{J}_{\mathrm{SC}}$ of $2.93 \mathrm{~mA} / \mathrm{cm}^{2}$ and $\mathrm{FF}$ of 0.47 . Conclusion: It can be seen from the current density logarithm and voltage diagram that the prepared $\mathrm{Au}$ nanoparticles produce Schottky barriers on the surface of $\mathrm{TiO}_{2}$. Due to the Schottky barrier, electrons were unable to go back to the dye molecules or electrolyte, thus effectively enhancing the electronic conversion efficiency.
\end{abstract}

Key words: Dye-Sensitized Solar Cells (DSSCs), $\mathrm{TiO}_{2}$ nanoparticles, natural dye, conversion efficiency, TiO nanotubes

\section{INTRODUCTION}

Energy technology is one of the most important technologies. In the 21 st century, technology has dominated people's life and people's consumption for energy will drastically soar. Moreover, environmental pollution has increasingly become a worldwide concern in the past few decades. Thus, how to enhance the efficiency of natural energy use and to recycle regenerated energy has become an important research field for developed countries (Rahoma, 2008). Although recent developments in solar energy

Corresponding Author: Ho Chang, Department of Mechanical Engineering, National Taipei University of Technology, No.1, Sec. 3, Chung-Hsiao E. Rd., Taipei 10608, Taiwan, China Fax: 886-2-27317191 
technology have allowed different countries to take more positive attitudes towards the prospects of solar energy, the current mainstream single-crystal silicon solar cells have not been popularized because of the high cost of materials (Green et al., 2009). In recent years, third-generation dye-Sensitized Solar Cells (DSSCs) have been developed, which are receiving increasing attention from researchers because of their low-cost materials. DSSCs are devices that convert visible light into electricity through the sensitization of wide-band-gap semiconductors. The operational principle of DSSCs is very simple: Photons interact with dye molecules to create excitons, which rapidly split to form electrons and holes. Electrons are attracted toward the photoelectrode and holes are transported by redox species at the nanoparticle surface in the electrolytes used in the DSSC. Dye-sensitized solar cells (DSSCs) have the advantages of simple fabrication, low cost and large area. Recent research has indicated that the photoelectric conversion efficiency of DSSCs can exceed previous solar cells by $10-11 \%$ (Gratzel, 2009; Wang et al., 2010). The photoelectrode is very important for obtaining highly efficient DSSCs (Park and Dhayal, 2009). $\mathrm{TiO}_{2}$ nanotubes can serve as the photoelectrode material because of their large surface area. $\mathrm{TiO}_{2}$ nanotubes can provide the large surface area required by the adsorbent dye and a path for electric current transfer. Moreover, their porous structure can facilitate electrolyte diffusion. Thus, $\mathrm{TiO}_{2}$ nanotubes with a one-dimensional nanostructure can replace photoelectrodes fabricated by conventional nanoparticles. Therefore, a photoelectrode fabricated from $\mathrm{TiO}_{2}$ nanotubes can smooth the transmission path for photoelectrons and reduce the possibility of the recombination of electrons and holes generated from photoelectrons and the electrolyte. Moreover, a photoelectrode fabricated from $\mathrm{TiO}_{2}$ nanotubes can increase the short-circuit current and the photoelectric conversion efficiency of DSSCs. In addition, $\mathrm{TiO}_{2}$ particles fabricated by different methods can increase the length of the path along which photons pass via the properties of light scattering if $\mathrm{TiO}_{2}$ particles with good properties of optical transmittance and scattering properties are used. Moreover, the probability of interactions between photons and the dye in the module can be increased and more electrons can be injected into the $\mathrm{TiO}_{2}$ semiconductor to increase the photoelectric conversion efficiency of DSSCs (Rashwan, 2005; Choi et al., 2010). However, obstacles of efficiency and stability still need to be overcome. Furthermore, metallic nanoparticles have special optical, electrical and magnetic properties and when metallic nanoparticles are smaller than nanoscale, quantum effects will be very significant (Sikong et al., 2010; Lim et al., 2010). With very high chemical energy, the surface of metallic nanoparticles exhibit resonance absorption when the incident light frequency approaches the surface plasma frequency of $\mathrm{Au}$ nanoparticles, causing the electrons of Au nanoparticles to move from their orbit to the surface plasma absorption band and thus easily producing chemical bonds with molecules. This phenomenon will directly affect optical properties and thus can be applied in DSSCs (Akbarzadeh et al., 2009; Gun et al., 2011). A key aspect of optimizing the sensitizer used for solar energy conversion is to increase the ratio of the rates of forward (injection) and reverse (recombination) electron transfer (Syres et al., 2010; Wenger et al., 2010). The transition metals of ruthenium polypyridyl complexes are typical and widely used dyes since they exhibit good visible light absorption, optical chemical properties and stability. The high energy conversion efficiency of the widely used N719 sensitizer [bis(tetrabutylammonium) cis-dithiocyanatobis (2,2'bipyridine-4- $\mathrm{COOH}, 4^{\prime}-\mathrm{COO}^{-}$), ruthenium(II)] and other related Ru-bipyridyl- based dyes derives from the spatial separation of the donor- the Lowest Unoccupied Molecular Orbital (LUMO), which is close to the $\mathrm{TiO}_{2}$ surface and the acceptor, the highest occupied molecular orbital (HOMO) resulting in injection which is much faster than recombination (Mohran, 2005; Liu and Wang, 2010). The transition metals of ruthenium polypyridyl complexes (N719) are typical and widely used dyes (Chae and Kang, 2011). But N719 dye is very expensive and so to overcome this problem we use natural pigment (Houari et al., 2005; Nguyen et al., 2010; Hwang et al., 2010; Chang et al., 2010) extracted from plants instead of N719. In nature, some fruits, flowers, leaves and so on show various colors and contain several pigments that can be easily extracted and then employed in DSSCs (Saelim et al., 2011). The leaves of most green plants are rich in chlorophyll and the application of this kind of natural dye has been frequently investigated in many related studies (Razak et al., 2011; Gomez-Ortiz et al., 2010; Ganesh et al., 2010). Anthocyanins are natural compounds that give color to fruits and plants and are also largely responsible for the purple-red color of autumn leaves and for the red color of flower buds (Furukawa et al., 2009). Bazargan adopted natural pomegranate juice for sensitization of nanocrystalline $\mathrm{TiO}_{2}$. The overall conversion efficiencies of fabricated DSSC found to be $1.5 \%$ for cell operated with platinum electrodeposited and $0.9 \%$ for carbon coated counter electrodes (Bazargan, 2010). Luo extracted the Canna indica L., Salvia splendens, Solanum nigrum L. to serve as 
photosensitizer and the energy conversion efficiency of the cells sensitized with dyes of C. indica L., $S$. splendens, cowberry and S. nigrum L. was $0.29 \%$, $0.26 \%, 0.13 \%$ and $0.31 \%$, respectively (Luo et al., 2009). Patrocinio used the extract of blueberries and Jaboticaba's skin to act as photosensitizer and the $\mathrm{V}_{\mathrm{OC}}$ of prepared DSSCs is $0.59 \mathrm{~V}$ and $0.45 \mathrm{~V}$ respectively (Patrocinio et al., 2009).

Common methods of preparing $\mathrm{TiO}$ nanotubes (Tnt) are anodic oxidation and hydrothermal treatment (Xie et al., 2010; Liao and Que, 2010). Due to its simplicity, hydrothermal treatment has become the main method of fabricating $\mathrm{TiO}_{2}$ nanotubes. Thus, this study uses hydrothermal treatment to prepare Tnt. To increase photoelectric conversion efficiency, this study adopts two different morphologies of $\mathrm{TiO}_{2}$ materials. The first layer of the DSSCs is a translucent film fabricated two times using the hydrothermal method, which can slightly enhance resistance and prevent the production of dark currents. The second layer is Tnt prepared by hydrothermal treatment and sintered at $550^{\circ} \mathrm{C}$ to fabricate the film. Because it is sintered at $550^{\circ} \mathrm{C}$, Tnt has better anatase crystal particles, increasing photoelectric conversion efficiency. The third layer uses a chemical reduction to synthesize Au nanoparticles and assemble $\mathrm{Au}$ nanoparticles on the surface of $\mathrm{TiO}_{2}$ to serve as Schottky barriers for the DSSCs by selfassembly. Schottky barriers can reduce the possibility of electrons being transmitted back from the semiconductor to the dye and electrolytes. H180, Tnt-C550 and Au nanoparticles are fabricated into three-layer compound films of photoelectrodes with bougainvillea, blueberry and mixtures of three natural dyes. The cells are tested and their performance is discussed.

\section{MATERIALS AND METHODS}

Preparation of Tnt: After $20 \mathrm{~g} \mathrm{NaOH}$ solids were put into a Perfluoroalkoxy (PFA) bottle, $50 \mathrm{~mL}$ of deionized water was added to fabricate a $10 \mathrm{M} \mathrm{NaOH}$ solution. After $\mathrm{NaOH}$ solids had dissolved, $1.5 \mathrm{~g}$ Degussa $\mathrm{P} 25 \mathrm{TiO}_{2}$ powder was added and stirred for 30 min at room temperature to disperse $\mathrm{TiO}_{2}$ powder evenly to a white suspension liquid. Then $70 \mathrm{~mL}$ of suspension liquid was poured into a Teflon container enclosed in a stainless autoclave and put in an oven at $130^{\circ} \mathrm{C}$ to react for $24 \mathrm{~h}$. After reacting, the autoclave was removed from the oven, the Teflon container was drawn and the suspension liquid was added into an alkaline solution. Then a white sediment was removed by a Teflon spoon and added into $500 \mathrm{~mL}$ of deionized water. After being filtered, $0.1 \mathrm{M} \mathrm{HNO}_{3}$ was added to repeatedly acidwash to $\mathrm{pH} 1.5$ and the mixed solution was put in an oven at $80^{\circ} \mathrm{C}$ to be dried for one day. Finally, the white sediment was ground into powder in an agate bowl to obtain TiO nanotubes (Tnt), as shown in Fig. 1.

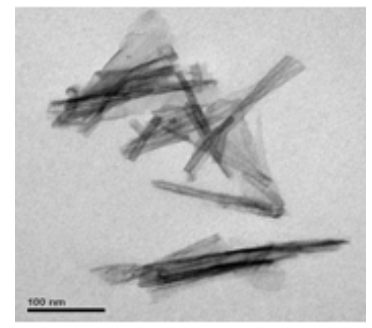

Fig. 1: HRTEM images of the prepared titania nanotubes (Tnt)

Preparation of photoelectrode for DSSC: The most popular commercial $\mathrm{TiO}_{2}$, called Degussa $\mathrm{P} 25 \mathrm{TiO}_{2}(\mathrm{P}-$ $\mathrm{TiO}_{2}$ ), containing approximately $85 \%$ anatase and $15 \%$ rutile, usually exhibits high photocatalytic activity. To prepare Tnt, $20 \mathrm{~g}$ of sodium hydroxide was placed in Perfluoroalkoxy (PFA) and $50 \mathrm{ml}$ of deionized water to prepare for a $10 \mathrm{M} \mathrm{NaOH}$ solution. Then $1.5 \mathrm{~g}$ of Degussa P25 powder was added to the $10 \mathrm{M}$ sodium hydroxide solution. The solution was stirred at room temperature for $30 \mathrm{~min}$ and then placed in an autoclave. After the autoclave was placed in an oven at $130^{\circ} \mathrm{C}$ for $24 \mathrm{hrs}$ to complete the reaction of this mixed solution, it was removed and allowed to cool to room temperature. Then the white sediment in the autoclave was extracted and added to $500 \mathrm{ml}$ of deionized water and the fluid was stirred and dispersed. After filtration, the sediment was washed repeatedly with $0.1 \mathrm{M}$ of $\mathrm{HNO}_{3}$ until it had a $\mathrm{pH}$ value of 1.5 . Tnt were added into $50 \mathrm{~mL}$ of $0.1 \mathrm{M}$ $\mathrm{HNO}_{3}$ and put into an oven to be processed twice with hydrothermal treatment at $180^{\circ} \mathrm{C}$. After reacting for 13 $\mathrm{h}$, the mixed solution was centrifuged for $30 \mathrm{~min}$ at $6000 \mathrm{rpm}$, acid solution was added, the white sediment was withdrawn by a Teflon spoon and put in the oven at $80^{\circ} \mathrm{C}$ to dry until the next day to obtain the productH180. To fabricate H180, Tnt prepared earlier was added to $0.1 \mathrm{M} \mathrm{HNO}_{3}$. The solution was placed in an oven at $180^{\circ} \mathrm{C}$ for $12 \mathrm{~h}$ for hydrothermal treatment. It was then centrifuged at $6000 \mathrm{rpm}$ for $30 \mathrm{~min}$ and the white sediment was extracted and dried in an oven at $80^{\circ} \mathrm{C}$ to obtain $\mathrm{TiO}_{2}$ nanoparticles. Nanoparticles formed by the hydrothermal treatment at $180^{\circ} \mathrm{C}$ are referred to as H180. H180 particles, sintered by two hydrothermal treatments, were added into $0.67 \mathrm{~mL}$ $0.1 \mathrm{M} \mathrm{HNO}_{3}$ and stirred violently at room temperature for $60 \mathrm{~min}$. The solution was then ultrasonically vibrated for $30 \mathrm{~min}$. Then, the mixed solution was added into Polyethylene Glycol (PEG) (M.W. = 20000), heated and stirred until completely dissolved and ultrasonically vibrated for $30 \mathrm{~min}$ to fabricate a translucent sol, which served as the paste spread by the doctor blade as the first layer. $\mathrm{TiO}_{2}$ particles prepared by hydrothermal treatment were sintered at $550^{\circ} \mathrm{C}$ and 
added into $0.67 \mathrm{~mL}$ deionized water and vibrated at room temperature for $60 \mathrm{~min}$ and then ultrasonically for $30 \mathrm{~min}$. The mixed solution was added into $0.04 \mathrm{~g}$ PEG (M.W. = 20000), heated and stirred until dissolved and ultrasonically vibrated for $30 \mathrm{~min}$ to fabricate a white colloidal dispersion, which acted as the paste spread the by doctor blade to prepare for the second layer. The third layer was fabricated by salt reduction to prepare for $\mathrm{Au}$ nanoparticles. The $100 \mathrm{~mL} 0.127 \mathrm{mM} \mathrm{HAuCl}_{4}$ was heated back to the boiling point and $1 \mathrm{ml}$ of $1 \mathrm{wt} \%$ Trisodium citrate $\left(\mathrm{C}_{6} \mathrm{H}_{5} \mathrm{Na}_{3} \mathrm{O}_{7}\right)$ solution was added as reducer. After violent stirring, the color of the mixed solution changed from yellow to purple. Continuously stirred and heated for one hour, the mixed solution was cooled down at room temperature. This study used the surface of $\mathrm{TiO}_{2}$ electrode layers to modify $\mathrm{Au}$ nanoparticles by the self-assembly method. $\mathrm{TiO}_{2}$ electrode layers were soaked and the mixed solution was combined with ammonia, hydrogen peroxide and water $\left(\mathrm{NH}_{4} \mathrm{OH}: \mathrm{H}_{2} \mathrm{O}_{2}: \mathrm{H}_{2} \mathrm{O}=1: 1: 5\right)$ for three hours so its surface consisted of negatively charged hydroxyl ( $\mathrm{Li}$ and Goel, 2010). Afterwards, ITO glass was soaked in $1 \mathrm{wt} \%$ Mercapto-propyl-tri-methoxy-silane (MPTMS) for 24 hours so the second layer of $\mathrm{TiO}_{2}$ film possessed sulfur blends. Au nanoparticles and thiol form covalent bonds to make Au nanoparticles stick to the second layer, thus accomplishing the fabrication of the photoelectrodes of DSSCs.

Preparation of natural dye: For anthocyanin, $10 \mathrm{~g}$ blueberry fruit was put in a $100 \mathrm{~mL}$ methyl alcohol/DI water /acetic acid mixed solution with the proportion of 25: $21: 4$ and heated for $5 \mathrm{~min}$ to extract anthocyanin at $50^{\circ} \mathrm{C}$ by water-resisting heating. For chlorophyll, $0.1 \mathrm{~g}$ bougainvillea was put in $100 \mathrm{~mL}$ non-toxic alcohol and heated for $5 \mathrm{~min}$ to extract chlorophyll at $50^{\circ} \mathrm{C}$ by water-resisting heating. The solid residue in the solution was poured through the filter paper in a clean and lightfree working environment to remove impurities in the dye solution, thus giving a pure and natural dye solution. Chlorophyll and anthocyanin dyes were also blended into a mixture with the volume ratio of $1: 1$. Finally, the prepared photoelectrode with the $\mathrm{TiO}_{2}$ and $\mathrm{Au}$ thin film was cut to $0.25 \mathrm{~cm}^{2}$ and then soaked in natural dye and ethanol solution. After soaking for $24 \mathrm{~h}$, the dye was completely adsorbed on the surface of each photoelectrode. A a three-layer photoelectrode (H180/TntC550/Au) were obtained by these steps.

Assembly and test of DSSC: The electrolyte utilized in this study was an Acetonitrile (ACN) solution containing $0.1 \mathrm{M}$ LiI, $0.05 \mathrm{M} \mathrm{I} 2$ and $0.5 \mathrm{M}$ TBP (tert- butylpyridine). A Pt counter electrode was coated on the FTO conductive glass by sputtering. The $\mathrm{TiO}_{2}$ electrode and counter electrode were tightly bonded and fixed by a binder clip to prevent the production of air bubbles, forming a sandwich DSSCs. A $150 \mathrm{~W}$ xenon (Xe) lamp was used to simulate sunlight (AM 1.5) and an I-V curve analyzer (Keithley 2400) was used to measure the performance of the prepared DSSCs. The open-circuit voltage $\mathrm{V}_{\mathrm{OC}}(\mathrm{V})$, short-circuit current density $\mathrm{J}_{\mathrm{SC}}\left(\mathrm{mA} / \mathrm{cm}^{2}\right)$, fill factor $(\mathrm{FF})$ and photoelectric conversion efficiency (\%) of each DSSC were also measured. Field-emission scanning electron microscope (FE-SEM; LEO-1530) images were used to measure and analyze the structure and morphology of the prepared $\mathrm{TiO}_{2}$ nanoparticles and three-layer thin-film photoelectrode. Transmission electron microscope (TEM; Hitachi H-7100) images were used to measure and analyze the structure and morphology of the prepared $\mathrm{Au}$ nanoparticles. X-Ray Diffraction (XRD; Siemens D5000) patterns were also employed to analyze the structure and characteristics of the fabricated $\mathrm{TiO}_{2}$ nanoparticles and $\mathrm{Au}$ nanoparticles. The absorption spectrum of chlorophyll dye, anthocyanin dye and mixed dye was measured using UV-vis spectrum equipment (JASCO V650). In addition, a I-V curve analyzer (Keithley 2400) was used to measure the Incident Photon-to-Electron Conversion Efficiency (IPCE) performance of the prepared DSSCs.

The photoelectric conversion efficiency of DSSC was inspected under the simulated sunlight source (AM1.5). With current-voltage (I-V) curve taken as the foundation, the Fill Factor (FF) was defined as follows:

$\mathrm{FF}=\mathrm{I}_{\max } \times \mathrm{V}_{\max } /\left(\mathrm{I}_{\mathrm{sc}} \times \mathrm{V}_{\mathrm{oc}}\right)$

Where:

$\mathrm{I}_{\max }$ and $\mathrm{V}_{\max }=$ The maximum output value of current and voltage respectively

$\mathrm{I}_{\mathrm{sc}}$ and $\mathrm{V}_{\mathrm{oc}} \quad=$ The short-circuit current and opencircuit voltage respectively

The total energy conversion efficiency was defined as follows:

$\eta=\mathrm{I}_{\mathrm{sc}} \times \mathrm{V}_{\mathrm{oc}} \times \mathrm{FF} / \mathrm{P}_{\text {in }}$

where Pin denotes the energy of incident photon.

$\mathrm{J}_{\mathrm{sc}}$ can be calculated by integrating the product of the incident photon flux density and the cell's IPCE over wavelengths used for light absorption by the dye. According to the equation used to describe the $\mathrm{J}_{\mathrm{sc}}$ for the photovoltaic cells with the assumption that the 
potential drop by series resistance in the cell is negligible, the Jsc is shown as follows (Lin et al., 2010; Chen et al., 2010):

$\mathrm{Jsc}=\int \mathrm{qF}(\lambda)(1-\mathrm{r}(\lambda)) \operatorname{IPCE}(\lambda) \mathrm{d} \lambda$

Where:

$\mathrm{q}=$ Electron charge

$\mathrm{F}(\lambda)=$ Incident photon flux density at wavelength $\lambda$

$\mathrm{r}(\lambda)=$ Incident light loss before reaching the $\mathrm{TiO}_{2}$ film in the cel

The IPCE is expressed as (Chou et al., 2010):

$\operatorname{IPCE}(\lambda)=\operatorname{LHE}(\lambda) \varphi_{\mathrm{e} \text {-inj }} \eta_{\text {Charge Collection }}=\operatorname{LHE}(\lambda) \Phi(\lambda)_{\mathrm{ET}}$

Where:

$\varphi_{\mathrm{e}-\mathrm{inj}}=$ Electron injection yield from the dye excited state into $\mathrm{TiO}_{2}$

$\eta_{\text {ChargeCollection }}=$ Charge collection efficiency at the back $\mathrm{SnO}_{2}$ electrode

$\Phi(\lambda)_{\mathrm{ET}} \quad=$ Defined as an electron-transfer yield, that is, a product of the electron injection yield and the charge collection efficiency

To effectively enhance the photoelectric conversion efficiency and fabricate DSSC photoelectrodes at a lower cost, in this study, we use $\mathrm{TiO}_{2}$ and $\mathrm{Au}$ nanoparticles with different morphologies for the thin-film photoelectrode of DSSCs. Tnt hydrothermally fabricated by $550^{\circ} \mathrm{C}$ calcinating treatment (Tnt-C550) and $\mathrm{TiO}_{2}$ nanoparticles (H180) obtained by exposing Tnt to two cycles of hydrothermal treatment $\mathrm{We}$ investigate the differences in structure, morphology and the level of light scattering of these three materials. In addition, to increase the light absorption of simulated sunlight by the photoelectrode, we use the three materials to design a three-layer structure for the thin film of the photoelectrode to enhance the overall effectiveness of DSSCs.

\section{RESULTS}

This study processed $\mathrm{TiO}_{2}$ powder (Degussa P25) and added $\mathrm{NaOH}$ to carry out hydrothermal treatment to form Tnt and analyze its characteristics. Samples of Tnt-C450, Tnt-C500 and Tnt-C550 sintered at $450^{\circ} \mathrm{C}$, 500 and $550^{\circ} \mathrm{C}$, respectively, were scanned by XRD patterns. Figure 2 is XRD spectrum and the results show that with higher sintering temperature, the intensity of the diffraction peak of anatase is reinforced. To acquire better nano-crystal anatase particles for DSSCs, the crystallinity of crystals plays a significant role in photoelectric conversion efficiency. Figure 3 shows the HRSEM images of Tnt processed at hydrothermal temperatures of $180^{\circ} \mathrm{C}$, it can be observed that the morophlogy of nanoparticles sample H180 with the particle size of about $20-35 \mathrm{~nm}$. H180 particles were inspected by XRD and the crystal structure of particles was observed.

Figure 4 shows that the XRD diffraction patterns of Tnt processed at hydrothermal temperatures of 180 and $200^{\circ} \mathrm{C}$. Comparing the XRD pattern after examination of the standard spectrum of a JCPDS (Joint Committee on Powder Diffraction Standards) card shows that the crystal structure of the fabricated particles was anatase $\mathrm{TiO}_{2}$ (JCPDS card no. 21-1272). Figure 4 shows that H180 has clear diffraction peaks of anatase and the crystalline of crystal has a decisive influence on the photoelectric conversion efficiency of DSSCs. Figure 5 shows the TEM images of $\mathrm{Au}$ nanoparticles, displaying that the morphology of $\mathrm{Au}$ nanoparticles is round, with an average size of $27 \mathrm{~nm}$. Au nanoparticles are examined by XRD tests and the results from Fig. 6 show clear Au peak. The above-mentioned tests demonstrate that $\mathrm{Au}$ nanoparticles can be fabricated and the effects of $\mathrm{Au}$ nanoparticles are good.

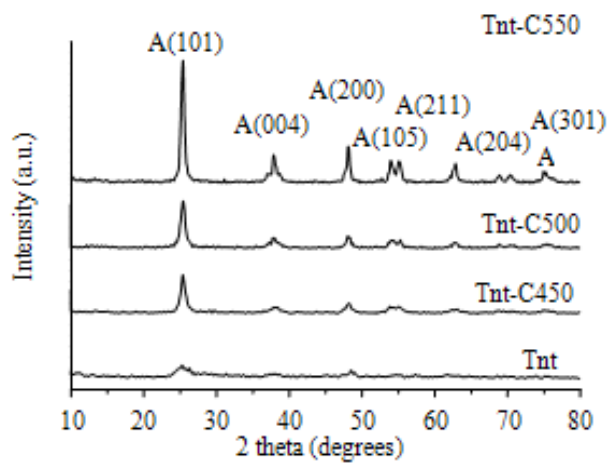

Fig. 2: XRD patterns of Tnt sintered at 450, 500 and $550^{\circ} \mathrm{C}$ respectively

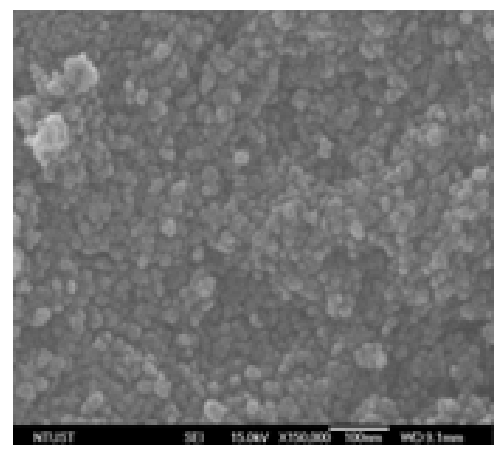

Fig. 3: FE-SEM images of H180 particles 


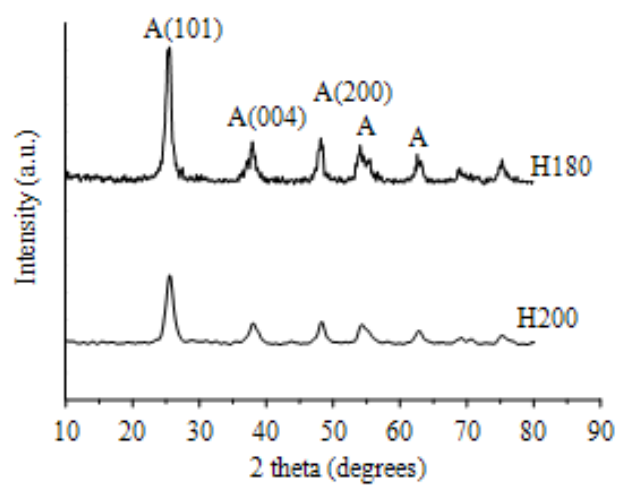

Fig. 4: XRD patterns of $\mathrm{H} 180$ and $\mathrm{H} 200$ particles

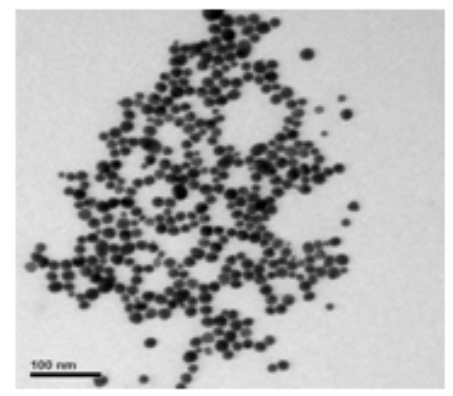

Fig. 5: TEM images of Au nanoparticles

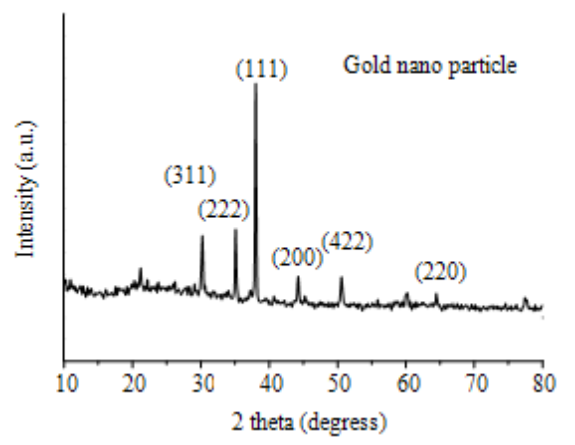

Fig. 6: XRD patterns of Au nanoparticles

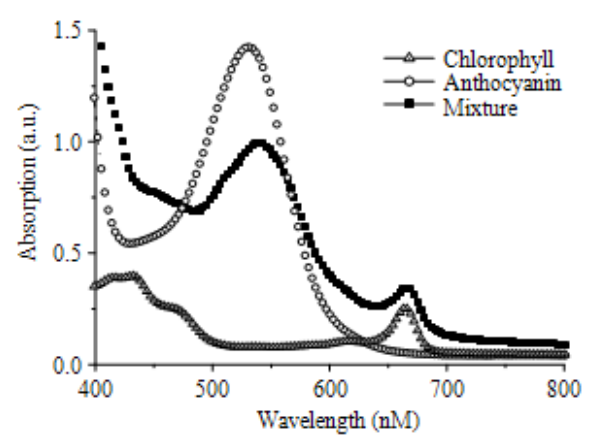

Fig. 7: Absorption spectrum of chlorophyll dye, anthocyanin dye and mixed dye

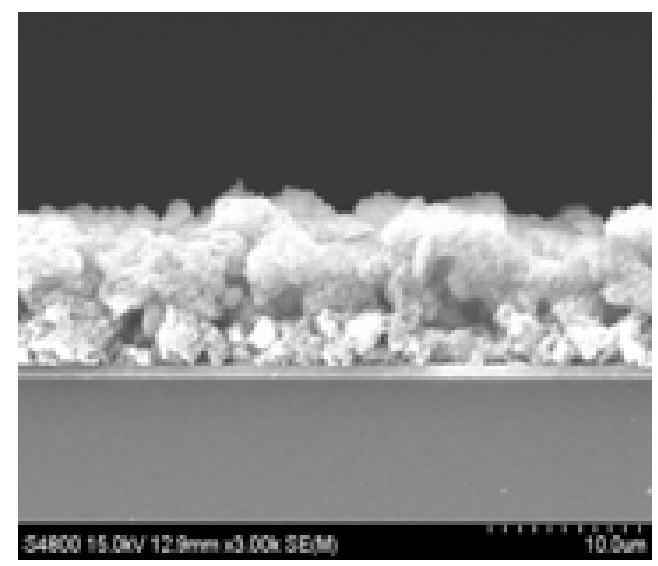

Fig. 8: FE-SEM image of a cross-section of a threelayer thin-film photoelectrode (H180/TntC550/Au)

Figure 7 shows the absorption spectra of chlorophyll dye, anthocyanin dye and the chlorophyll dye and anthocyanin dye mixture at a volume ratio of 1 : 1 . Results show that the absorption intensity of mixed dye is highest of the three, with a range of 400-700 nm. However, absorption intensity of the mixed dye is a half of that of anthocyanin dye within the range of 500-550 $\mathrm{nm}$. It is speculated that the absorption of chlorophyll dye is lower within this wavelength range, affecting the absorption intensity of mixed dye.

Figure 8 is the tomography of the three layers of film spread on photoelectrodes, showing that the total thickness of all the films of photoelectrode is $14 \mu \mathrm{m}$. The Keithley 237 voltage and power flow measuring meter can be used to measure whether or not the Schottky barriers affect dark-field voltage, current value and the diagram of current density logarithm and voltage. If the diagram shows a linear relationship, the interface phenomenon of Schottky barriers exists. If the curve tends to be linear with the coefficient approaching 1 , the electrical interface is close to interface of the Schottky barrier, corresponding to ideal Schottky-type interfacial reaction. The results from Fig. 9 show that when the voltage is less than $0.3 \mathrm{~V}$, the linear relationship does not exist in the relationship between the current logarithm and voltage. Thus, the electrical phenomenon does not correspond to a Schottky barrier. When the voltage is more than $0.3 \mathrm{~V}$, the Schottky barrier is more apparent and the relationship between the current logarithm and voltage is approaches linearity. 
Am. J. Nanotech., 1 (1): 13-22, 2010

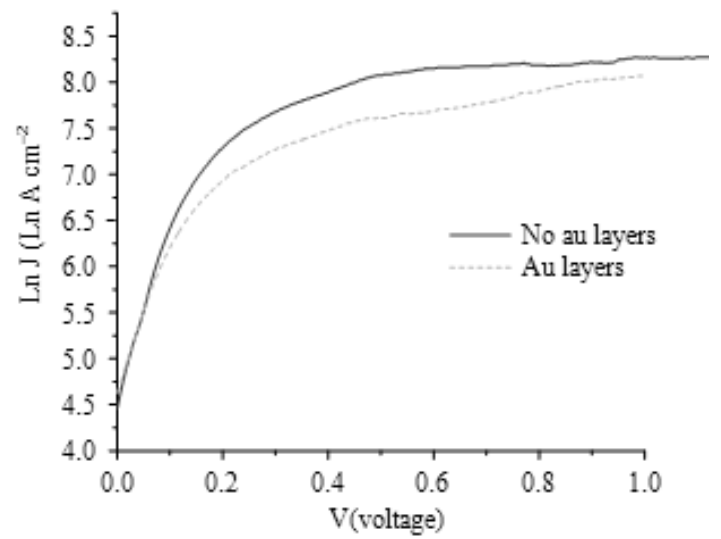

Fig. 9: J-V curve of $\mathrm{Au}$ loaded on a $\mathrm{TiO}_{2}$ layer in the dark field for the DSSCs

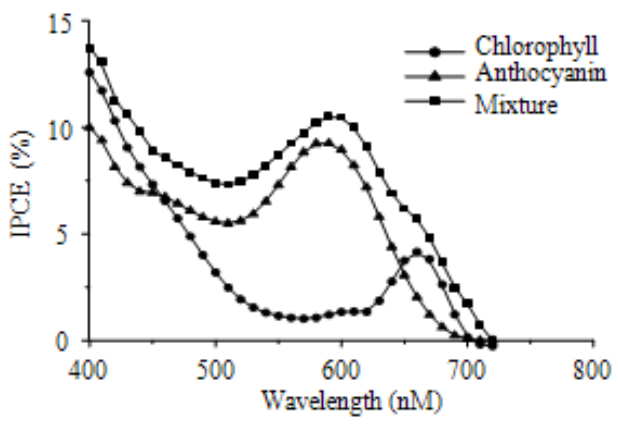

Fig. 10: IPCE of chlorophyll dye, anthocyanin dye and mixed dye

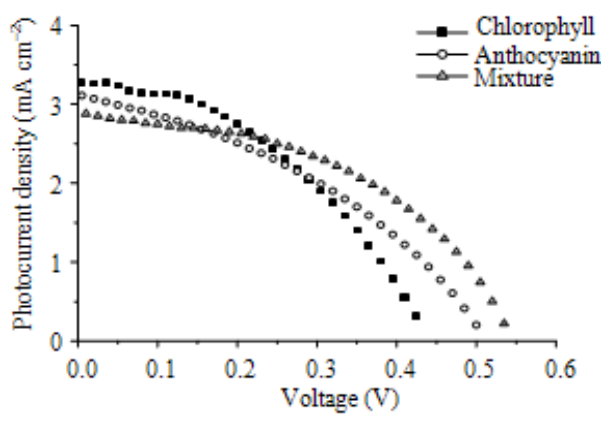

Fig. 11: Photocurrent voltage characteristics of chlorophyll dye, anthocyanin dye and mixed dye

Table 1: Photoelectrochemical parameters of multilayer electrodes in DSSCs

\begin{tabular}{lllll}
\hline Dye & $\mathrm{V}_{\mathrm{oc}}(\mathrm{V})$ & $\mathrm{J}_{\mathrm{sc}}\left(\mathrm{mA} \mathrm{cm}^{-2}\right)$ & $\mathrm{FF}(\%)$ & $\eta(\%)$ \\
\hline Chlorophyll & 0.5 & 3.23 & 41 & 0.618 \\
Anthocyanin & 0.52 & 3.14 & 38 & 0.638 \\
Mixture & 0.56 & 2.93 & 47 & 0.75 \\
\hline
\end{tabular}

Figure 10 shows the IPCE diagram for chlorophyll dye, anthocyanin dye and a mixture of the two with a volume ratio of 1: 1 as the cocktail dyes. As can be seen from Fig. 7 and Fig. 10, the anthocyanin dye has higher absorption range at wavelength of 400-630nm, making IPCE value higher than that of chlorophyll dye in the range of visible light. In addition, the IPCE value of chlorophyll dye is higher than anthocyanin dye at wavelength of $400-450 \mathrm{~nm}$. Nevertheless the IPCE value of anthocyanin dye is much higher than chlorophyll dye at wavelength of 550-630 nm.

The photovoltaic performance of the prepared DSSCs summarized in Table 1 and the results shown in Fig. 11. The results from Table 1 show the data acquired from measuring the photoelectric conversion efficiency of DSSCs. As can be seen from Fig. 11 and Table 1, the conversion efficiency of the DSSCs prepared with chlorophyll dye from bougainvillea extract is $0.618 \%$, with an open-circuit voltage $\left(\mathrm{V}_{\mathrm{OC}}\right)$ of $0.5 \mathrm{~V}$, short-circuit current density $\left(\mathrm{J}_{\mathrm{SC}}\right)$ of $3.23 \mathrm{~mA}$ $\mathrm{cm}^{-2}$ and fill factor (FF) of 0.41 . The conversion efficiency of the DSSCs prepared with anthocyanin dye from blueberry extract is $0.638 \%$, with $\mathrm{V}_{\mathrm{OC}}$ of $0.52 \mathrm{~V}$ and $\mathrm{J}_{\mathrm{SC}}$ of $3.14 \mathrm{~mA} \mathrm{~cm}^{-2}$ and $\mathrm{FF}$ of 0.38 . Furthermore, the conversion efficiency is $0.75 \%$ for the mixture of chlorophyll and anthocyanin dyes with $\mathrm{V}_{\mathrm{OC}}$ of $0.56 \mathrm{~V}$ and $\mathrm{J}_{\mathrm{SC}}$ of $2.93 \mathrm{~mA} \mathrm{~cm}^{-2}$ and $\mathrm{FF}$ of 0.47 . It can be seen from the Table 1 that the combination dye improves the photoelectric conversion efficiency of DSSCs.

\section{DISCUSSION}

The H180 nanoparticles was fabricated into translucent paste in this study through two hydrothermal treatments, using a doctor blade to spread the first translucent and dense layer. Adding a dense layer leads to a dark current for DSSCs and spreading a translucent layer can slightly enhance resistance and block the loss of dark current by elevating resistance and thus, increasing photoelectric conversion efficiency. This dense layer is formed by $\mathrm{TiO}_{2}$ and leads to fewer errors with the energy levels of the second-layer film-TntC550. The second layer is Tnt sintered at 550 by hydrothermal treatment and spread by a doctor blade to prepare for a porous $\mathrm{TiO}_{2}$ film. Then Au nanoparticles are assembled on the surface of $\mathrm{TiO}_{2}$ to serve as the third layer by self-assembly to act as the Schottky barrier of DSSCs. The transmittances spectra of the H180 and Tnt-C550 and Au which have optical transmittances of about 60, 50 and $45 \%$ and, respectively. On the basis of the optical transmittance properties revealed from the data of the transmittances spectra, we employ the H180, Tnt-C550 and Au 
samples to design the photoelectrode as a multilayer nanoscale thin film and the photoelectric conversion efficiency of the prepared DSSCs is measured. In addition, photoelectric conversion value occurs in the wavelength of 400-700 $\mathrm{nm}$ range and the mixed dye can provide wider incident light conversion area, making its IPCE value higher than that of anthocyanin dye and chlorophyll dye in the range of visible light. This is because the mixed dye absorbs light at wavelength of 400-700 nm and increasing incident light conversion values in this area and maintains the incident light conversion characteristics of anthocyanin dye in the $500-650 \mathrm{~nm}$ range. DSSCs of mixed dye in the $\mathrm{IPCE}_{\max }$ of $600 \mathrm{~nm}$ are $11.8 \%$, demonstrating that the mixed dye can increase photoelectric conversion.

\section{CONCLUSION}

From the experimental results and discussion, the following conclusions can be drawn:

- The prepared Tnt are sintered at temperatures of 450,500 and $550^{\circ} \mathrm{C}$ and the results show that higher the sintering temperatures give a stronger diffraction peak of anatase

- It can be seen from the current density logarithm and voltage diagram that the prepared $\mathrm{Au}$ nanoparticles produce Schottky barriers on the surface of $\mathrm{TiO}_{2}$

- Results from IPCE and UV-VIS diagram show that the mixed dye increases incident light conversion values at the wavelength of $400-700 \mathrm{~nm}$ and maintaining the incident light conversion characteristics of anthocyanin dye in the 500-650 $\mathrm{nm}$ range. In addition, the $\mathrm{IPCE}_{\max }$ is $11.8 \%$ at the wavelength of $600 \mathrm{~nm}$ for the DSSCs with mixed dye and demonstrating that the mixed dye can increase photoelectric conversion

- The photocurrent-photovoltage curve shows that photoelectric conversion efficiency of DSSCs in this study can reach $0.75 \%$

\section{ACKNOWLEDGMENT}

This study was supported by the National Science Council of Taiwan, Republic of China under the project grant: NSC 98-2221-E-027-084.

\section{REFERENCES}

Akbarzadeh, A., D. Zare, A. Farhangi, M.R. Mehrabi and D. Norouzian et al., 2009. Synthesis and characterization of gold nanoparticles by tryptophane. Am. J. Appl. Sci., 6: 691-695.
Bazargan, M.H., 2010. Performance of nano structured dye-sensitized solar cell utilizing natural sensitizer operated with platinum and carbon coated counter electrodes. Int. J. Chem. Tech. Res., 2: 615 619. http://sphinxsai.com/sphinxsaiVol_2No.1/Che mTech_Vol_2No.1/ChemTech_Vol_2No.1PDF/C $\mathrm{T}=96 \% 20 \% \overline{2} 8615-619 \% 29 . \mathrm{pdf}$

Chae, J. and M. Kang, 2011. Cubic titanium dioxide photoanode for dye-sensitized solar cells. J. Power Sour., 196: 4143-4151. DOI: 10.1016/J.JPOWSOUR.2010.12.109

Chang, H., H.M. Wu, T.L. Chen, K.D. Huang and C.S. Jwo et al., 2010. Dye sensitized solar cell using natural dyes extracted from spinach and ipomoea. J. Allo. Compd., 495: 606-610. DOI: 10.1016/J.JALLCOM.2009.10.057

Chen, C.M. Chen, C.H. Chen, S.J. Cherng and T.C. Wei, 2010. Electroless deposition of platinum on indium tin oxide glass as the counterelectrode for dye-sensitized solar cells. Mater. Chemi. Phys. 124: 173-178. $\quad$ DOI: 10.1016/J.MATCHEMPHYS.2010.06.014

Choi, H., J.J. Kim, K. Song, J. Ko and M.K. Nazeeruddin et al., 2010. Molecular engineering of panchromatic unsymmetrical squaraines for dyesensitized solar cell applications. J. Mater. Chem., 20: 3280-3286. DOI: 10.1039/B926863D

Chou, C.S., C.I. Huang, R.Y. Yang and C.P. Wang, 2010. The effect of SWCNT with the functional group deposited on the counter electrode on the dye-sensitized solar cell. Adv. Powd. Tech., 21: 542-550. DOI: 10.1016/J.APT.2010.02.008

Furukawa, S., H. Iino, T. Iwamoto, K. Kukita and S. Yamauchi, 2009. Characteristics of dye-sensitized solar cells using natural dye. Thin Sol. Fil., 518: 526-529. DOI: 10.1016/J.TSF.2009.07.045

Ganesh, T., J.H. Kim1, S.J. Yoon, B.H. Kil and N.N. Maldar et al., 2010. Photoactive curcumin-derived dyes with surface anchoring moieties used in $\mathrm{ZnO}$ nanoparticle-based dye-sensitized solar cells. Mater. Chem. Phys., 123: 62-66. DOI: 10.1016/J.MATCHEMPHYS.2010.03.062

Gomez-Ortiz, N.M., I.A. Vazquez-Maldonado, A.R. Perez-Espadas, G.J. Mena-Rejon and J.A. AzamarBarrios et al., 2010. Dye-sensitized solar cells with natural dyes extracted from achiote seeds. Sol. Energy Mater. Sol. Cel., 94: 40-44. DOI: 10.1016/J.SOLMAT.2009.05.013

Gratzel, M., 2009. Recent advances in sensitized mesoscopic solar cells. Acc. Chem. Res., 42: 17881798. DOI: $10.1021 /$ ar900141y 
Green, M.A., K. Emery, Y. Hishikawa and W. Warta, 2009. Solar cell efficiency tables (version 33). Prog. Photovol. Res. Appl., 17: 85-94. DOI: 10.1002/pip. 880

Gun, J., V. Gutkin, O. Lev, H.G. Boyen and M. Saitner et al., 2011. Tracing gold nanoparticle charge by electrolyte-insulator-semiconductor devices. J. Phys. Chem. C., 115: 4439-4445. DOI: 10.1021/jp109886s

Houari, M., M. Saidi, D. Tabet, P. Pichat and H. Khalaf, 2005. The Removal of 4-chlorophenol and dichloroacetic acid in water using Ti-, Zr- and Ti/Zr-pillared bentonites as photocatalyst. Am. J. Appl. Sci., 2: 1136-1140. DOI: 10.3844/ajassp.2005.1136.1140

Hwang, K.J., W.G. Shim, S.H. Jung, S.J. Yoo and J.W. Lee, 2010. Analysis of adsorption properties of N719 dye molecules on nanoporous $\mathrm{TiO}_{2}$ surface for dye-sensitized solar cell. App. Surf. Sci., 256: 5428-5433. DOI: 10.1016/J.APSUSC.2009.12.128

Li, L. and R.K. Goel, 2010. Role of hydroxyl radical during electrolytic degradation of contaminants. J. Hazard. Mater. 181: 521-525. DOI: 10.1016/J.JHAZMAT.2010.05.045

Liao, Y. and W. Que, 2010. Preparation and photocatalytic activity of $\mathrm{TiO}_{2}$ nanotube powders derived by a rapid anodization process. J. All. Compo., 505: 243-248. DOI: 10.1016/J.JALLCOM.2010.06.038

Lim, S.J., Y.S. Kang and D.W. Kim, 2010. Photovoltaic performance of dye-sensitized solar cells assembled by in-situ chemical cross-linking. Electrochem. Commun., 12: 1037-1040. DOI: 10.1016/J.ELECOM.2010.05.018

Lin, C.J., W.Y. Yu and S.H. Chien, 2010. Transparent electrodes of ordered opened-end $\mathrm{TiO}_{2}$-nanotube arrays for highly efficient dye-sensitized solar cells. J. Mater. Chem., 20: 1073-1077. DOI: 10.1039/B917886D

Liu, Y. and J. Wang, 2010. Co-sensitization of $\mathrm{TiO}_{2}$ by $\mathrm{PbS}$ quantum dots and dye N719 in dye-sensitized solar cells. Thin Solid Films, 518: e54-e56. DOI: 10.1016/J.TSF.2010.03.126

Luo, P., H. Niu, G. Zheng, X. Bai and M. Zhang et al., 2009. From salmon pink to blue natural sensitizers for solar cells: Canna indica L., Salvia splendens, cowberry and Solanum nigrum L. Spectrochim. Acta A Mol. Biomol. Spectrosc., 74: 936-942. DOI: 10.1016/J.SAA.2009.08.039

Mohran, H., 2005. Cyclic volta metric Study of alizarin yellow $\mathrm{R}$ and some analogous arylazo compounds in DMF and in aqueous media. Am. J. Appl. Sci., 2: 1610-1614. DOI: 10.3844/ajassp.2005.1610.1614
Nguyen, P.T., A.R. Andersen, E.M. Skou and T. Lund, 2010. Dye stability and performances of dyesensitized solar cells with different nitrogen additives at elevated temperatures-Can sterically hindered pyridines prevent dye degradation? Sol. Energy Mater. Sol. Cel., 94: 1582-1590. DOI: 10.1016/J.SOLMAT.2010.04.076

Park, K.H. and M. Dhayal, 2009. High efficiency solar cell based on dye sensitized plasma treated nanostructured $\mathrm{TiO}_{2}$ films. Electrochem. Commun., 11: 75-79. DOI: 10.1016/J.ELECOM.2008.10.020

Patrocinio, A.O.T., S.K. Mizoguchi, L.G. Paterno, C.G. Garcia and N.Y.M. Iha, 2009. Efficient and low cost devices for solar energy conversion: Efficiency and stability of some natural-dyesensitized solar cells. Synth. Metals, 159: 23422344. DOI: 10.1016/J.SYNTHMET.2009.08.027

Rahoma, U.A., 2008. Utilization of solar radiation in high energy intensive of the world by PV system. Am. J. Environ. Sci., 4: 121-128. DOI: 10.3844/ajessp.2008.121.128

Rashwan, F.A., 2005. Determination of A.C. impedance spectroscopic and cyclic voltammetric behavior of some heterocarbonyl compounds in both aprotic and aqueous media. Am. J. Appl. Sci., 2: 1153-1157. DOI: 10.3844/ajassp.2005.1153.1157

Razak, N. A., S. M. Tumin and R. Tajuddin, 2011. Effect of temperature on the color of natural dyes extracted using pressurized hot water extraction method. Am. J. Appl. Sci., 8: 45-49. DOI: 10.3844/ajassp.2011.45.49

Saelim, N., R. Magaraphan and T. Sreethawong, 2011. $\mathrm{TiO}_{2} /$ modified natural clay semiconductor as a potential electrode for natural dye-sensitized solar cell. Ceramics Inter., 37: 659-663. DOI: 10.1016/J.CERAMINT.2010.09.001

Sikong, L., B. Kongreong, D. Kantachote and W. Sutthisripok, 2010. Photocatalytic activity and antibacterial behavior of $\mathrm{Fe}_{3}{ }^{+}$-doped $\mathrm{TiO}_{2} / \mathrm{SnO}_{2}$ Nanoparticles. Ene. Res. J., 1: 120-125. http://www.thescipub.com/pdf/10.3844/erjsp.2010. 120.125?PHPSESSID $=\mathrm{a} 2 \mathrm{c} 27 \mathrm{ddb} 5 \mathrm{e} 03758 \mathrm{ec} 3735 \mathrm{e} 9$ ef9a6408c

Syres, K., A. Thomas, F. Bondino, M. Malvestuto and M. Gratzel, 2010. Dopamine adsorption on anatase $\mathrm{TiO}_{2}(101)$ : A photoemission and NEXAFS spectroscopy study. Langmuir, 26: 14548-14555. DOI: $10.1021 /$ la1016092

Wang, H., P.G. Nicholson, L. Peter, S.M. Zafeeruddin and M. Gratzel, 2010. Transport and interfacial transfer of electrons in dye-sensitized solar cells utilizing a $\mathrm{Co}$ (dbbip)2 redox shuttle. J. Phys. Chem. C., 114: 14300-14306. DOI: 10.1021/jp105753k 
Wenger, S., P.A. Bouit, Q. Chen, J. Teuscher and D.D. Censo et al., 2010. Efficient electron transfer and sensitizer regeneration in stable $\pi$-extended tetrathiafulvalene-sensitized solar cells. J. Am. Chem. Soc., 132: 5164-5169. DOI: $10.1021 / \mathrm{ja} 909291 \mathrm{~h}$
Xie, K., L. Sun, C. Wang, Y. Lai and M. Wang et al., 2010. Photoelectrocatalytic properties of $\mathrm{Ag}$ nanoparticles loaded $\mathrm{TiO}_{2}$ nanotube arrays prepared by pulse current deposition. Electrochim. Acta, 55: 7211-7218. DOI: 10.1016/J.ELECTACTA.2010.07.030 